\title{
The Incidence of Government Expenditures on Education and Health: Microeconomic Evidence from Pakistan
}

\author{
Ahmed Nawaz Hakro* and Muhammed Akram**
}

\begin{abstract}
This paper has analyzed the incidence of government expenditures on bealth and education by using the benefit incidence approach. Recent household level data from the Pakistan Standards of Living Measures (PSLM) has been used to calculate the incidence for Pakistan overall, and at provincial and regional levels, of different education and health services. GINI and concentration coefficients have been used to measure the benefit inequalities of public expenditure. The results demonstrate that education expenditures are progressive in overall Pakistan. The progressiveness hypothesis regarding health expenditure is accepted partially, as the expenditure is progressive for Pakistan overall, but regressive at regional and provincial level of services. Efforts should be directed towards the horizontal and vertical equity in the allocation of resources both at the provincial and regional levels, and greater targeting of rural and lowincome groups can make the expenditure programs more effective and result oriented.
\end{abstract}

Key Words: Benefit Incidence, Health, Education, and Pakistan

\section{Introduction and Background}

A vast body of literature exists on the incidence of government expenditures. Most of the studies have used the benefit incidence approach on household data. Findings demonstrate that public expenditures are either progressive or regressive and the share of different income groups varies depending on the distribution of the benefits of the public expenditures across region, caste, religions, gender etc, [see e.g. Christian (2002), Rasmus et al. (2001), Younger (1999), Demery and Verghis (1994), Jorge (2001), Roberts (2003), Hyun (2006), David and Stephen (2000), Gupta et al. (1998, 2002),

\footnotetext{
* Visiting Scholar, Department of Economics, University of Glasgow, Glasgow, UK.

**Lecturer, International Institute of Islamic Economics, International Islamic University Islamabad.
} 
Flug et al. (1998), Lamiraud et al. (2005), SPDC (2004), ESCAP (2003), Norman (1985), Castro et al. (2000), Hamid et al. (2003), Sakellariou and Harry (2004), Shahin (1999) etc]. The studies which demonstrate progressiveness such as Rasmus et al. (2001) focus on the incidence of the public expenditure on education and health (Mozambique data) and resulted in the poorest quintile of income groups receiving 14 percent of total education spending; the poorest half receives 36 percent, and the richest quintile receives 33 percent. Hyun (2006) by using household data from Thailand concluded that government subsidies (in-kind transfer income) benefit the poor and can reduce poverty. With a data set from Ecuador, Younger (1999) used a combination of benefit and behavioral approaches and found that public spending improves health and education indicators in developing countries. Cross country studies such as Gupta et al. (2002) used 56 data sets and showed that the increase in public expenditures on health and education are associated with improvement in both access to and enrollment in schools, and reduce the mortality rates in infants and children.

Other studies that determine the regressiveness of the incidence of public expenditure such as Norman (1985) concluded that many government expenditures on education and health benefit upper income more than the lower income groups. Castro-Leal et al. (2000) examined public spending on curative care in several African countries and found that spending favored mostly the better off rather than the poor. Hamid et al. (2003) has also shown evidence of substantial cross-country heterogeneity. The subsidies in education can be progressive or regressive; normally these subsidies are progressive at the lower levels of education and regressive at higher levels. Demery and Verghis (1994), using a data set from Kenya, concluded that primary education spending was strongly progressive in absolute as well as in relative terms while secondary and university education spending were regressive in absolute terms, and weakly progressive relative to. In-kind transfers tend to be progressive unless there are serious targeting problems.

Justification of government expenditures on education based on the social rate of return e.g. Pascharropolous (1994) and World Bank (1995) found that the return is highest on primary education followed by secondary and tertiary education. At the same time, evidence suggests that spending on tertiary education in many countries is higher than primary and secondary education. Lanjouw and Martin (1999) by using data from rural India have argued that marginal spending affects the poor more than average spending, and when programs are expanded or reduced the composition of beneficiaries tends to change. Shahin (1999) showed that inequity in benefits from education spending in Côte d'Ivoire is greater amongst the female population than in the male population - although this is not as true 
for health in Guinea. There exists a strong negative relation between income and expenditure shares. Bjo" $\mathrm{rn}$ and $\mathrm{Li}$ (2004) in China based on data from households in 18 provinces in 1988 and in 1995 also proved this same result.

A few points deserve to be discussed. First, the impact of the level of public expenditures on human capabilities is a debated point, because not all studies have found an empirical link between the two. The link between successfully addressing poverty issues and spending is not primarily a function of the percent of GDP that is devoted to total spending on health and education, but depends foremost on the intra-sectoral allocation to health and education spending. Evidence demonstrates that countries with high shares of education spending devoted to primary and secondary levels recorded higher persistence rates through grade four and higher primary and secondary enrolment rates. Infant and child mortality rates are lowest in countries with high shares of health spending devoted to primary (preventive) care. Second, policy makers must confront the nature and magnitude of the fiscal incidence. The policy choices require information about which groups are likely to pay for and which groups are more likely to benefit from expenditures. Policy makers have many questions about how to reduce the burden of taxation for lower income groups and about how to increase the effectiveness of public expenditures. How can public spending be targeted in order to improve the conditions of the poor? Hence, incidence analysis provides some critical information to help policy makers achieve a more equitable distribution of income and improve effectiveness of public policy.

The literature is substantial in understanding the question of the incidence of public expenditure across the developing as well as developed countries. However, largely, the available literature has been conducted on old data sets of household surveys, and the studies are not updated or done afresh. Second, there is a lack of comparisons of incidence across countries on one hand and incomparability of cross country results on the other hand. Third, the impact on different groups or populations, or gender- or regionwise impact of incidence are not taken into consideration, factors emphasized by Seldon and Wasylenko (1992). Fourth, literature on the incidence of the public expenditure and its distribution in Pakistan ${ }^{1}$ is scarce. Two studies e.g. Sabir (2003) and Hussain et al. (2003) have been conducted in this context, but both studies suffer from a number of problems. For Example, Sabir (2003) has used a three-step methodology on

${ }^{1}$ Health and education is the lowest priority of public expenditure in Pakistan. The country spends 0.5 percent of GNP on health and 2.1 percent of GDP on education GOP (2005-06), though wide inequality of distribution is existed. 
the data of HIES 2001-02. Only for education expenditure does the study segregate subsidies gender- and region-wise and concluded that the government subsidies directed toward primary education are pro-poor in all four provinces. However, females are more disadvantaged in terms of access to primary education. Government subsidies directed towards higher education are poorly targeted and the poorest income group receives less than the richest income group and indeed favor those who are better off. The study also falls short of classifying the analysis based on the rural/urban dimension. The other study, Hussain et al. (2003), has used secondary data sources, taking the averages of the expenditures for the incidence analysis. The study has used the Representation Index and GINI coefficient technique for the allocation of resources to the education sector district-wise and inequalities among districts in the allocation of the resources to the education sector. They concluded that there exist no disparities between the districts' allocations of funds to education. This study has not used GINI and concentration coefficients to measure the income inequalities and was limited to allocation of education expenditures only.

The literature discussed above is not very comprehensive in dealing with the question in the Pakistani context for a number of reasons; both studies were conducted on old data sets by taking averages of secondary sources, second, both studies only take into account education for their analysis and used different instruments. Third, health expenditure is not included in their set of variables; fourth, Hussain et al. (2003) falls short in analyzing the inequalities of distributions of expenditure on income or using GINI and concentration coefficients to determine the progressiveness or regressiveness of expenditures.

This aim of this study is to analyze the incidence of public expenditures in Pakistan on education and health by using the latest household survey data from Pakistan Social and Living Standards Measurement Survey (PSLM) (Round-1) 2004-05, collected by the Federal Bureau of Statistics Pakistan. By using a recent micro data set, this paper highlights the nature of incidence, and indirectly provides a guideline to view the extent to which health and education policy targets have been successfully achieved, who benefits and how much? What kind of inequalities exist region- and income-wise? Additionally, by measuring the inequalities in the distribution of the benefits of expenditures, the study will have policy implications as to how the expenditure programs can be made more effective. 
The rest of the paper is organized as follows. Section II consists of methodology, and is followed by Section III, which enlists the results, and Section IV contains the conclusion and policy recommendations.

\section{Methodology}

\section{The Benefit Incidence Approach}

The benefit incidence approach is called the classic approach or nonbehavioral approach, which was pioneered by twin World Bank studies conducted by Selowasky (1979) for Colombia and Meerman (1979) for Malaysia, Castro et al. (2000), Demery and Verghis (1994) and several other studies mentioned earlier.

The purpose of benefit incidence is to identify who benefits from public spending and how much. The benefit incidence approach measures how much the income of a household would have to be raised if the household had to pay for the subsidized public services at full cost. The beauty of this approach is that it uses the information on the cost of the publicly provided goods and services, taking into consideration the uses of goods and services by the different income groups and finally finds out the estimates of the distribution of benefits. The individual beneficiaries are grouped by their income level, but they can also be grouped by geographical area, ethnic group, urban and rural location, gender and so on. In analyzing the incidence of public expenditures in health and education in Pakistan, this grouping has been formulated on the basis of income, rural/urban and province/region wise.

In practice, the conduct of incidence analysis generally involves three steps.

These steps are:

1- Obtain the estimates of the unit cost or subsidy embedded the provision of a particular public service. For this step data is usually extracted from public expenditure accounts. For example, the data on per student cost or subsidy by level of schooling can be obtained from the budget.

2- Impute the subsidies to the individual or household identified as user of the service by using information available on use by different income groups. For example enrollment rates in public schools across population deciles ordered by income level 
ranging from poor to rich or clinic visits as reported by different households in consumer expenditure surveys.

3- Aggregate individuals or households in groups ordered by income or expenditure or any other grouping of interests such as race or gender, distribute the benefits among the different groups and arrive at an estimate of the incidence of per capita subsidies accruing to each group.

\section{Public Subsidy}

The service-specific public subsidy received by an individual is,

$$
S_{k}=q_{k} c_{k}-f_{k}
$$

Where $S_{k}$ represents the subsidy received by the individual on service $k, q_{k}$ indicates the quantity of service $k$ utilized by the individual, $c_{k}$ represents the unit cost of providing $k$ in the region where individual resides, and $f_{k}$ represents the amount paid for $k$ by the individual.

$$
\mathrm{S}_{\mathrm{j}}=\sum_{\mathrm{i}=1}^{4} \mathrm{H}_{\mathrm{ij}} \frac{\mathrm{E}_{\mathrm{i}}}{\mathrm{H}_{\mathrm{i}}}=\sum_{i=1}^{4} \frac{H_{i j}}{H_{i}} E_{i}
$$

Where $S_{j}$ is the value of the total health or education subsidy imputed to group $j, H_{i j}$ represents the number of health visits of group $j$ to the health or education facilities at the level $i$ ( $i$ representing primary, secondary, higher or professional education in education and hospitals and clinics, mother child or preventive measures in health), $H_{i}$ is the total number of such visits (across all groups) and $E_{i}$ is the government spending on education or health at level $i$ (with fees and other cost recovery netted out). Note that $E_{i} / H_{i}$ is the unit subsidy of funding a health consultation or attending a school at level $i$. Then the share of the total health or education subsidy $E_{i}$ accruing to the group is given by

$$
\mathrm{s}_{\mathrm{j}}=\sum_{\mathrm{i}=1}^{4} \frac{\mathrm{H}_{\mathrm{ij}}}{\mathrm{H}_{\mathrm{i}}}\left(\frac{\mathrm{E}_{\mathrm{i}}}{\mathrm{E}}\right)=\sum_{i=1}^{4} b_{i j} \cdot p_{i}
$$

Clearly, equation 3 (and indeed overall inequality in the benefit incidence) is determining two proximate factors: the share of the group in total health consultation or attending a school at each level of the facility $b_{i j}$ and the share of the each level of the health care or education level in total 
health spending or total education spending $P_{i}$. The value $b_{i j}$ reflects the household health care decision or to attend a school, whereas the value $P_{i}$ reflects the government spending allocation.

There are two useful methods for analyzing expenditure incidence results by income group: concentration curves and the concentration index. To draw a concentration curve, the population is usually arranged from lowest to highest income. Since our purpose here is to determine the effect of government expenditures, the population is arranged in ascending order of income i.e., from poorest to richest. This ranking is based on income deciles which are not equal in size in terms of numbers of households. A concentration curve shows the cumulative proportion of expenditures going to cumulative proportions of the population. So it is similar to a Lorenz curve.

However, unlike the Lorenz curve, which shows the cumulative proportion of income earned by the cumulative population, a concentration curve can lie above the diagonal: The poorest 40 percent of the population cannot earn more than 40 percent of income, but they can get more than 40 percent of spending on social grants.

The concentration curve in figure 1.1, that lies above the Lorenz curve but below the diagonal are least progressive or weakly equity enhancing i.e., it would redistribute the resources even if funded by proportional taxes, and the poorer are comparatively better off when considering both their income and public spending, compared to considering only their income. The concentration curve which lies above the diagonal shows that spending is targeted at the poor, i.e. it is strongly equity-enhancing or per capita progressive or pro-poor i.e., the poor benefit more than proportionately to their numbers. If a concentration curve lies everywhere above the 45-degree line, the benefit is per capita progressive, indicating that poorer households receive disproportionately large shares of the benefit. Concentration curves that lie below the Lorenz curve are classified as regressive. The concentration coefficient estimates the inequalities in the distribution of government expenditures and is calculated in same way as the GINI coefficient. The only difference is that the concentration coefficient is calculated by keeping the income group the same. The concentration coefficient can lie in range of -1 and 1 while the GINI coefficient lies between 0 and 1 . If the concentration coefficient is lower than the GINI coefficient, it shows that expenditures are more evenly distributed than income and vice versa. 


\section{Figure No.1.1}

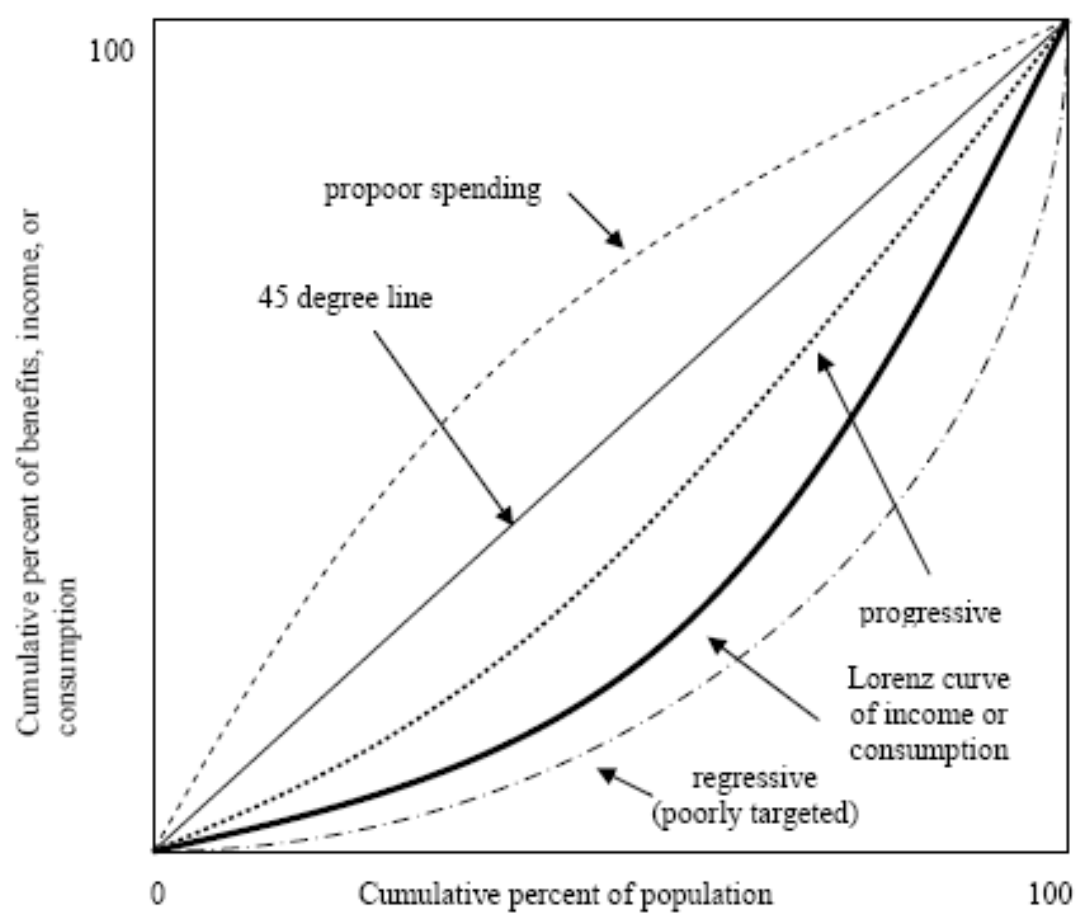

This concept has been taken from Sahn and Younger (2000) who have examined the progressive nature of social sector expenditures in eight subSaharan African countries. They employ dominance tests, complemented by extended GINI/concentration coefficients, to determine whether health and education expenditures redistribute resources to the poor. According to them, concentration curves are a useful way to summarize information on the distributional benefits of government expenditures, and statistical testing of differences in curves is important.

\section{Procedure of calculating net government subsidy}

Net government subsidies to a household have been calculated by deducting the total individual expenditures incurred on education or health services from the total per-household government expenditures in the provision of services. Using this net subsidy, the GINI and concentration coefficients have been calculated to check the nature of the incidence of government expenditures on services. Theoretically, if the concentration coefficient is lower than the GINI coefficient, the expenditures on services are progressive or pro-poor and vice versa. Net subsidies have been used to 
calculate the shares of different income quintiles in government expenditures on services to measure the inequalities in the expenditure shares of different income groups.

The following data sets have been taken from different government sources.

- The information on the use of the publicly provided health and education services, income of the household and the individual expenditures on health and education have been obtained from Pakistan Social and Living Standards Measurement Survey (Round-1) 2004-05, Federal Statistics Division Government of Pakistan.

- The data on enrolment in different educational institutions have been taken from Pakistan Education Statistics 2004-05, Ministry of Education Pakistan.

- To find out per capita expenditure in health, the data on population has been obtained from National Institute of Population Study (2005).

- Total expenditures on health and education in Sindh is taken from Budget 2006-07, Vo1. III, Current Expenditure on Education \& Health, Finance Department, Government of Sindh. ${ }^{2}$

- Total expenditures on health in NWFP is taken from Demand for Grants Current Expenditure for 2006-07, Vo1. III, (PART-A), Government of NWFP.

- Total expenditures in health and education in Punjab is taken from Estimate of Charged Expenditure and Demand for Grants (Current Expenditure) Vo1. I (Fund No. PC 21016-PC 21016) 2006-07.

- Total expenditures on education in NWFP is taken from Demand for Grants Current Expenditure for 2006-07, Education Vo1. III, (PARTA) Provincial, Government of NWFP Finance Department.

- Total expenditures in health and education in Balochistan is taken from Demand for Grants and Current Expenditure (New Accounting) for the Year 2006-07, Education Vol. III-A) Provincial, Government of Balochistan Finance Department.

\footnotetext{
${ }^{2}$ Grant requests are usually accepted as the budget expenditure.
} 
- Total expenditures in health and education in Pakistan data is taken from Demand for Grants and Appropriations 2006-07, Government of Pakistan, Finance Division, Islamabad.

- The percentage distribution of the total expenditures in different sectors of health and education the percentage distribution has been taken from PRSP, Annual progress Report FY 2004-06, PRSP Secretariat, Finance Division Government of Pakistan, September 2005 .

\section{Hypotheses}

The following hypotheses will be tested.

i) Government expenditures in health and education are progressive in Pakistan.

ii) There exist large inequalities in the distribution of government expenditures at different levels of the health and education sectors in Pakistan overall and at provincial and regional (urban and rural) levels.

\section{Results and Discussion}

\section{Expenditure Incidence: Education ${ }^{3}$}

The results on the incidence of expenditures at different levels of education in Pakistan are presented in Table-1.1. Government expenditures in Pakistan overall, provincial and regional levels, and at all levels of education (primary, secondary, higher and professional education) is progressive with the exceptions of large inequalities in rural NWFP and rural Sindh. The expenditure in rural Baluchistan is regressive, and largely unequal as well. All the GINI coefficients are higher than the concentration coefficient ${ }^{4}$, which implies that expenditures are distributed evenly.

\footnotetext{
${ }^{3}$ Government is spending 2.1 percent of the GDP on education; out of it 42.18 percent on primary education, 23.46 percent on secondary and 12.31 percent on higher education, GOP (2005-06).

4 The concentration coefficient shows the inequalities in the distribution of the government expenditures. This is calculated in the same as the GINI coefficient, which shows the income inequalities. The difference is that we calculate the concentration coefficient keeping income group the same. The concentration coefficient can lie in the range of -1 and 1 while the GINI coefficient lies between 0 and 1 . If the concentration coefficient is lower than the GINI coefficient it shows that expenditures are more evenly distributed than income and vice versa.
} 


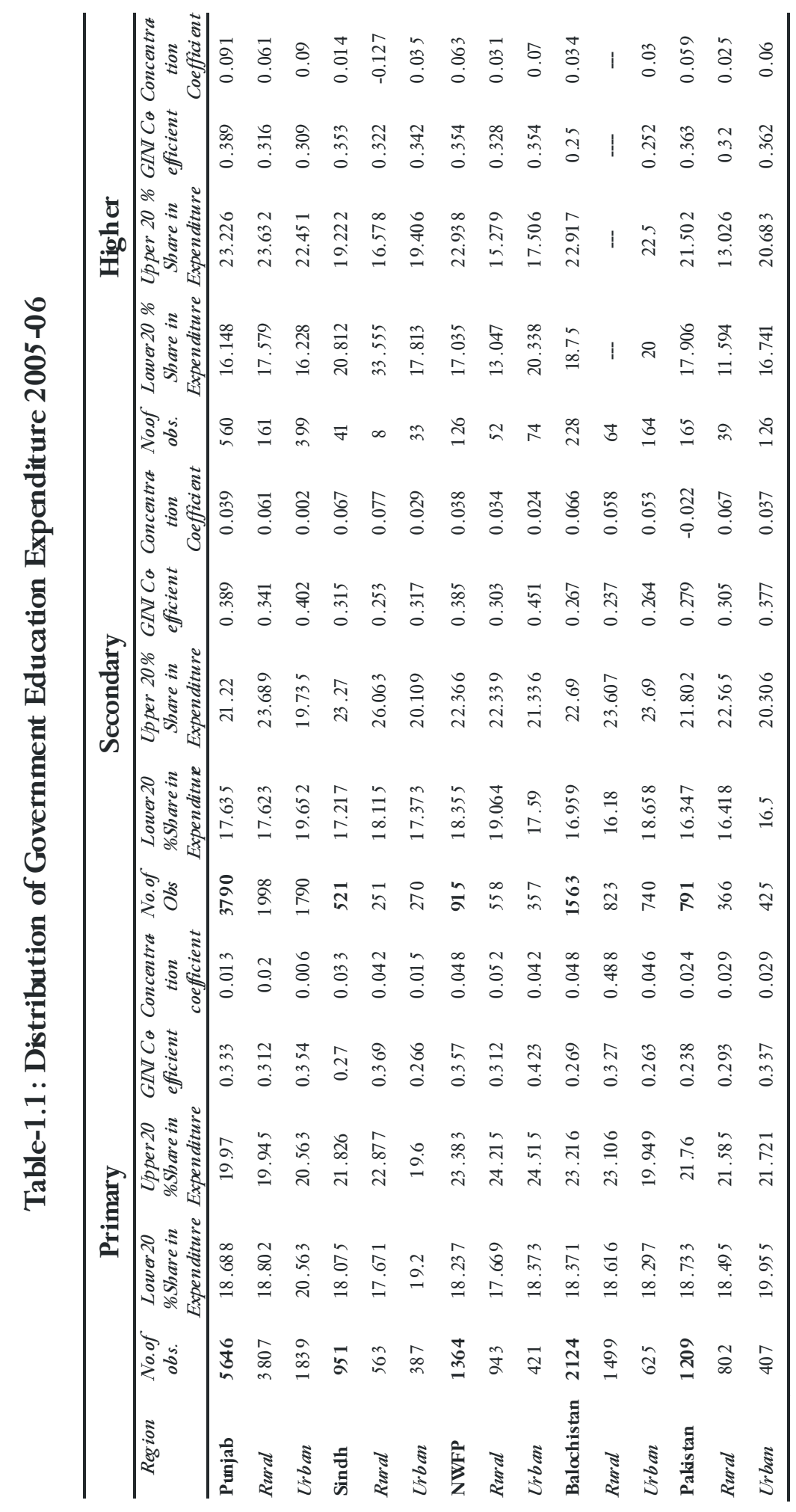


In primary education, the share of the poorest 20 percent of the population ranges from 17 to 20 percent while the share of the wealthiest 20 percent of people ranges from 19 to 23 percent in Pakistan overall. At the provincial level, the share of the lowest quintile and the highest quintile are almost in the same range as in Pakistan overall. The share of the lowest quintile is lower than the highest quintile; it is more skewed in rural NWFP and Sindh, where there exist larger inequalities in the shares of the upper income groups and lowest income groups, as compared to other provinces. In rural Balochistan the expenditures are regressive, as the concentration coefficient is larger than the GINI coefficient.

In secondary education, the income-wise comparisons shows that the share of the lowest quintile in secondary education expenditure is 16.34 percent while the share of the highest quintile is 21.80 percent in Pakistan overall. At the provincial level, the share of lower income groups in public expenditures ranges from 17 percent to 20 percent and 20 to 24 percent for higher income groups in all provinces. The coefficient of concentration is lower than the GINI coefficient in all the provinces. This implies that the lower income groups are getting more benefits than higher income groups from the government expenditures in the secondary education. The share of the poorest quintile is lower than the richest quintile at the provincial level and in Pakistan overall. In urban Punjab, it is equally distributed, so that the upper and lower income quintiles receive equal benefits. However, large inequalities exist in rural Sindh, where the upper quintile receives 26 percent as compared to the lower quintile that receives only 18 percent.

Higher educational expenditure is also progressive in Pakistan overall as well as at the provincial level. The higher education expenditures are pro low-income groups in Pakistan as the concentration coefficient and GINI coefficient demonstrate. In Pakistan overall and at the provincial level, both rural and urban, the concentration coefficient is less than the GINI coefficient. This implies that expenditures are more equally distributed than income. Lower income groups are experiencing greater opportunities to access to higher education.

Although the public expenditures are progressive in higher education, there exists a large variation in its distribution. The share of the lower quintile is 18 percent as compared to 21 percent for the higher quintile in Pakistan overall. Urban areas have more access as compared to the rural areas. In rural areas, the lower quintile share is just 12 percent whereas in urban areas it is 17 percent. The share of the highest quintile is 13 percent in rural Pakistan while it is 20 percent for urban areas. At the provincial level, the share of the lower quintile is higher than the share this quintile has in Pakistan overall. It 
is highest in Sindh and especially in rural Sindh, where the share of the lower quintile is 34 percent, which is higher than all urban and rural areas in Pakistan. The share of the highest quintile varies from 17 percent to 24 percent at the provincial level. It is highest for rural Punjab and lowest for rural NWFP, which is 15 percent of the total expenditures in higher education.

Unavailability of information and the relatively small number of observations on professional education in rural/urban and overall Balochistan has restricted our analysis of public expenditures on professional education. The remaining three provinces and Pakistan overall has been incorporated in our analysis, which is reported in Table-1.2. The public expenditures on professional education are progressive. The lower quintile's share in these expenditures is 19 percent as compared to the upper quintile's share, which is 12 percent.

Table-1.2: Professional/ Technical Education

\begin{tabular}{lcccc}
\hline Region & $\begin{array}{c}\text { Lower20 \%Share } \\
\text { in Expenditure }\end{array}$ & $\begin{array}{c}\text { Upper20 \%Share } \\
\text { in Expenditure }\end{array}$ & $\begin{array}{c}\text { GINI } \\
\text { Coefficient }\end{array}$ & $\begin{array}{c}\text { Concentration } \\
\text { Coefficient }\end{array}$ \\
\hline Pakistan & 19.06 & 12.47 & 0.41 & 0.06 \\
Punjab & 18.18 & 21.21 & 0.34 & 0.03 \\
Sindh & 19.04 & 19.04 & 0.40 & 0.00 \\
NWFP & 17.14 & 14.28 & 0.23 & 0.25 \\
Balochistan & NA & NA & NA & NA \\
\hline
\end{tabular}

$\mathrm{N} / \mathrm{A}=$ Not available

The expenditures on professional/technical education at the provincial level are progressive in all the provinces of Pakistan except in the NWFP, where it is regressive. Otherwise the public expenditures are pro low income groups in Punjab and Sindh. The regressiveness of public expenditures in professional education may be due to a number of factors, for e.g. access to technical education and institutions (since most of the technical institutes are in cities) geography, customs, taboos, or social political upheavals, and level of income differences in urban and rural NWFP. Also, largely the technical educational institutes are in cities where low income groups in cities are fewer than the low income groups in rural NWFP. The shares of the lower quintile in professional/technical education 
expenditures are in the range of 12 to 19 percent while the share of the higher quintile is in the range of 14 to 21 percent.

\section{Expenditure Incidence: Health}

The net subsidies at the household level have been calculated first by subtracting total individual expenditure on the use of medical facilities at the household level from the total government expenditures in the provision of medical services at the household level. This net subsidy has been used to analyze the nature of the incidence of government expenditures on health. The net subsidy has been used to calculate the shares of different quintiles, the GINI, and concentration coefficients in order to derive progressiveness or regressiveness of expenditures on health. Variations in the shares of different quintiles provide a measure of the inequalities in the benefit of public expenditures on health received by these quintiles.

The distribution of health expenditures at different levels of health e.g. mother childcare level, general hospitals, and clinics level, and on preventive measures is skewed. There exist large inequalities across regions and at the different levels of health expenditures. In mother childcare, the health expenditure distribution is progressive which implies that lower income groups are getting greater benefits from these expenditures as compared to the higher income groups ${ }^{5}$. This is due to the fact that the lower income groups are unable to afford the costs at the private maternity hospitals, and prefer to avail government hospital services instead where the costs are significantly lower. Second, the high-income groups prefer to utilize private health serves where better quality facilities are available as they can afford them. The share of the lower quintile in the mother child expenditures is 11 percent and the higher quintile's share is 25 percent for Pakistan overall (see Table No. 1.3). Although the share of lowest income groups is lower, overall expenditures at mother child care level is significantly pro-low income groups and, thus progressive. The GINI coefficient is higher than the concentration coefficient.

At the provincial level, the expenditures at the mother childcare level in Punjab and Sindh are highly regressive. The share of highest quintile is almost 8 times higher than the lowest quintile's share in Punjab, and it is almost 5 times higher in Sindh. On the other hand, mother childcare expenditures are progressive in NWFP.

\footnotetext{
${ }^{5}$ The data on Balochistan in the case of mother child was not available and data on the remaining provinces and Pakistan overall was to not sufficient to undertake the analysis at rural and urban level. The analysis of the available information is presented in Table-1.3.
} 
Prevention is better than cure. The Government of Pakistan is spending most of its health budget on preventive measures and health facilities. Public expenditures on preventive measures and health facilities are progressive, as lower income groups are getting a higher share as compared to higher income groups. The GINI coefficient is higher than the concentration coefficient; this implies that the expenditures are more equally distributed than income. Expenditures on preventive measures and health facilities are pro low-income groups.

The share of the lower quintile in preventive expenditure is 22 percent as compared to 20 percent for the highest quintile in Pakistan overall. At the urban and rural levels in Pakistan, the share of the lower income group is lower than the higher income group. At the provincial level, the expenditures on preventive measures and the health facilities level are progressive. The GINI coefficients are higher than the concentration coefficients in all the provinces. However, small variations in the upper quintile and lower quintile shares exist. This difference is higher than the other provinces particularly in Punjab and Balochistan. Expenditures are almost 7 points higher for the upper quintile group as compared to the lower quintile group in Punjab overall, and it is 9 points higher for rural Punjab. In Sindh and NWFP nominal differences in the shares of lower and upper income quintile groups in preventive measures and health facilities expenditures exist.

Public expenditures at the level of general hospitals and clinics are progressive in Pakistan overall, both at the rural and urban levels. The share of the lower quintile at hospitals and clinics level is 16 percent and 20 percent for the highest quintile in Pakistan overall. In rural areas, the share of the lower quintile is almost double the share of the highest quintile, but for urban areas the situation is in reverse. In rural areas, the public hospitals and clinics are very few while the population is large, and low income groups have normally little options other than these clinics or dispensaries. That may be the reason the poor income groups get more benefits from the public expenditures as compared to the high income groups. The high income groups in rural areas have access to hospitals and specialized institutions in urban areas and normally prefer to get treatment from private hospitals located in urban areas.

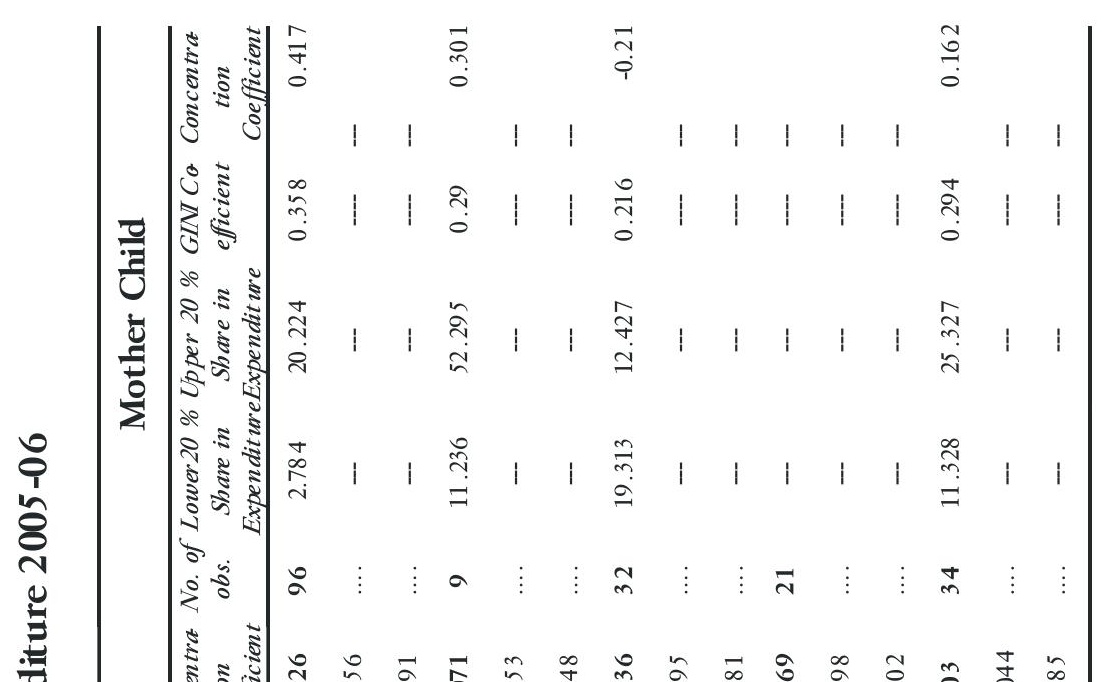


At the provincial leve1, the expenditures are progressive in Punjab, Sindh and NWFP. These expenditures are regressive in Balochistan overall, rural Balochistan and for rural Punjab.

In rural Punjab, the share of the lower quintile in public expenditures on hospitals and clinics is almost 8 times less than the share of the higher quintile. In rural Punjab, the expenditures on hospitals and clinics are regressive.

\section{Conclusions and Policy Implications}

The hypothesis that educational expenditure is progressive in Pakistan overall can be accepted. The progressiveness hypothesis regarding health expenditure is accepted partially as overall health expenditure in Pakistan is progressive but regressive at the regional and provincial levels. The hypothesis regarding the existence of large inequalities in the shares of the different quintiles in health and education expenditures cannot be rejected. The educational expenditures in overall Pakistan as well as in all the provinces in Pakistan (except primary education in rural Balochistan and professional education in NWFP) are progressive in nature. Overall, the low-income segment of the population is reaping greater benefits from the expenditures on different areas of education subheads. The expenditures on health are overall progressive in Pakistan, while it is regressive in some subhead level expenditures of health at provincial and regional levels. At the mother childcare level, expenditures are regressive in Punjab and NWFP and spending on general hospitals and clinics level are regressive in rural Punjab and in Balochistan. In the health sector more inequalities prevail in the shares of the lower and upper quintiles in government expenditures. The expenditures on mother childcare and general hospitals and clinics are regressive at least at the provincial level. The rural-urban inequalities are more profound.

Government expenditures on education are progressive while the health sector government expenditures are partially progressive as the share of the lower quintile is lower than the upper quintile.

Since inequalities in the shares of different quintiles in the benefits of government expenditures on health and education in Pakistan are widely accepted, horizontal and vertical equity in the allocation of resources to health and education both at provincial and regional level can make the expenditure programs in health and education more effective and result oriented. This means that government redistribution programs should be targeted more to specific (low income) and rural populations or improve the 
access to these services. Specific targeting tools might be fee waivers, scholarships, cash transfers, or in-kind transfers and may result in the increase of subsidies to low income groups and enhance the share of lower quintiles and rural people. As Pakistan is among the countries with low ranking on the Human Development index (HDI), investment in human capital will result in significant returns. The increase in expenditures as a percentage of GDP on health, education and other social sector expenditures and their effective management will result in positive benefits in the long run. 


\section{References}

Bjo"rn. G and LI, S., 2004, "Expenditures on education, health care and poverty in rural China”. China Economic Review 15 (2004) 292-302.

Castro-Leal, F., Demery, J. and Mehra, K., 2000, "Public Spending on Health care in Africa: Do the poor benefit?" Bulletin of the World bealth Organization, 78(1).

Christian, M., 2002, "Education and Health Expenditure, and Development: The Cases of Indonesia and Peru” Development Centre Studies, OECD Report.

David. E. Sahn and Stephen D. Younger, 2000, "Expenditure Incidence in Africa: Microeconomic Evidence” Fiscal Studies Vol. 21, No. 3.

Demery, L. and Verghis, M., 1994, "The Incidence of Education Expenditure in Kenya", Education and social policy department, World Bank.

ESCAP, 2003, "The Role of Public Expenditure in the provision of Education and Health". Economic and Social Survey of Asia and the Pacific (ESCAP).

Flug, K. Spilimbergo, A. and Wachtenheim, E., 1998, "investing in Education: Do Economic Volatility and Credit Constraints Matter?" Journal of Development Economics, Vol .55.

Government of Balochistan, 2006, 'Demand for Grants and Current Expenditure (New Accounting)' for the Year 2006-07, Education Vol. III-A) Provincial Government of Balochistan Finance Department.

Government of NWFP, 2006, 'Demand for Grants Current Expenditure for 2006-07, Education' Vo1.III, (PART-A) Provincial Government of NWFP Finance Department.

Government of NWFP, 2006, Demand for Grants Current Expenditure for 2006-07, Vo1.III, (PART-A) Government of NWFP, Peshawar.

Government of Pakistan, 2005, PRSP, Annual progress Report FY 2004-06, PRSP Secretariat, Finance Division, Government of Pakistan September. 
Government of Pakistan, 2006, 'Demand for Grants and Appropriations 200607 Government of Pakistan, Finance Division Islamabad.

Government of Pakistan, 2006, 'Economic Survey of Pakistan 2005-06' Ministry of Finance, Islamabad.

Government of Pakistan, 2006, 'Pakistan Education Statistics 2004-05', Ministry of Education Islamabad, Pakistan

Government of Pakistan, 2006, 'Pakistan Social and Living Standards Measurement Survey (Round-1) 2004-05', Federal Bureau of Statistics, Islamabad.

Government of Punjab, 2006, 'Estimate of Charged Expenditure and Demand for Grants (Current Expenditure)' Vol.I (Fund No. PC 21016-PC 21016) 2006-07.

Government of Sindh, 2006, Budget 2006-07, Vo1.III, Current Expenditure on Education \& Health Finance Department, Government of Sindh, Karachi.

Gupta, S., clements, B., Tiongson, E., 1998, "Public Spending on Human" Development Finance and Development 35, pp $10-13$.

Gupta, S., Marijn, V.and Erwin, R.T., 2002, “The effectiveness of government spending on education and health care in developing and transition economies” European Journal of Political Economy, Vol. 18, 717-737.

Hamid, R.D, Erwin R.T, and Sawitree S.A., 2003, "How Useful Are Benefit Incidence Analyses of Public Education and Health Spending?” IMF Working Paper 227, WP/03/227.

Husain F., Qasim, M.A. and Sheikh, K.H., 2003, "Analysis of Public Expenditure on Education in Pakistan”, The Pakistan Development Review 42:4 Winter 2003.

Hyun H. S., 2006, "Assessing the Pro-poorness of the Government Fiscal policy in Thiland". International Poverty Center, UNDP, working Paper No.15.

Jorge, M., 2001, "The Impact of Budgets on the Poor: Tax and Benefit Incidence" International Studies Program, Working Paper 01-10, Andrew Young School of Policy Studies Georgia State University. 
Lamiraud, K., Frikkie, B. and Xenia, S., 2005, "Impact of Social Health Protection on Access to Health Care, Health Expenditure and Impoverishment: A Case Study of South Africa”. Global Campaign on Social Security and Coverage for All, ESS Paper No. 23 Geneva, International Labour Office.

Lanjouw, P. and Martin, R., 1999, "Benefit Incidence, Public Spending, Reforms, and the Timing of Program Capture". The World Bank Economic Review, vol. 13(2): 257-73.

Meerman, J., 1979, Public Expenditure in Malaysia: Who Benefits and Why, New York: Oxford University Press.

Norman Gemme11, 1985, "The incidence of Government Expenditure and Redistribution in the United Kingdom” Economica, New Series, Vo1.52, No. 207, pp. 336-344.

Pascharropolous, G., 1994, "Returns to investment in education: a global update. World Development 22, pp 1325 -1343.

Rasmus, H., Kenneth S. and Finn, T., 2001, "Public Spending and Poverty in Mozambique", UNU/WIDER project on New Fiscal Policies for Growth and Poverty Reduction.

Roberts, John, 2003, "Poverty Reduction Outcomes in Education and health: Public Expenditure and Aid”. Working paper No. 210, Center for Aid and Public Expenditure, Overseas Development Institute.

Sabir, M., 2003, "Gender and Public Spending on Education in Pakistan: A Case Study of Disaggregated Benefit Incidence” Paper No.48 presented at conference of Social Policy Development Centre (SPDC).

Sahn, D. and Stephen, Y., 2000, "Expenditure incidence in Africa: microeconomic evidence”, Fiscal Studies, Vol. 21, pp. 329-347.

Sakellariou, C. and Harry, A. P., 2004, "Incidence Analysis of Public Support to the Private Education Sector in Cote d Ivoire" World Bank Policy Research Working Paper 3231.

Selden, Thomas M and Michael Wasylenko, 1992, "Benefit Incidence Analysis in Developing Countries” World Bank Policy Research Working Paper No 1015 . 
Selowsky, 1979, 'Who benefits from government expenditure? A case study of Colombia, Oxford University press.

Shahin, Y., 1999, "How Equitable is Public Spending on Health and Education?” Background Paper to WDR 2000/1.

SPDC, 2004, Social Development in Pakistan 2004: Combating Poverty: Is Growth Sufficient?' Annual report 2004, Karachi.

World Bank, 1995, "Priorities and Strategies for Education" A World Bank Review. World Bank, Washington, DC.

Younger, S. D., 1999, "The Relative Progressivity of Social Services in Ecuador”. Public Finance Review, 13 (2). 